\title{
Infrastructure and climate change: a study of impacts and adaptations in Malawi, Mozambique, and Zambia
}

\author{
Paul S. Chinowsky • Amy E. Schweikert • \\ Niko L. Strzepek • Ken Strzepek
}

Received: 1 April 2013 / Accepted: 23 July 2014 / Published online: 22 August 2014

(C) UNU-WIDER 2014

\begin{abstract}
The African Development Bank has called for $\$ 40$ Billion USD per year over the coming decades to be provided to African countries to address development issues directly related to climate change. The current study addresses a key component of these issues, the effect of climate change on the road infrastructure of Malawi, Mozambique, and Zambia. The study incorporates a stressor-response approach to estimate the effects of projected precipitation, temperature, and flooding changes on the paved and unpaved road infrastructure of these countries. The paper highlights the result of running 425 climate scenarios for each road type and policy option from 2010 to 2050 . Based on this broad analysis, it is estimated that the three southern African countries are facing a potential \$596 million price tag based on median climate scenarios to maintain and repair roads as a result of damages directly related to temperature and precipitation changes from potential climate change through 2050. The challenge for policy makers is to determine the potential risk that a country is facing based on the uncertainties associated with the multiple aspects of climate change modeling.
\end{abstract}

\section{Introduction}

The African Development Bank has called for \$40 Billion USD per year over the coming decades to be provided to African countries to address development issues directly related to climate change (Kaberuka 2009). These costs are required to assist in the adaptation to climate change and its associated effects. Costs are of particular concern in developing countries, where the additional funds needed to address climate change concerns are limited or nonexistent. The limitations on these available funds are challenging developing countries to identify the threats that are posed by climate change, develop adaptation approaches to the

This article is part of a Special Issue on "Climate Change and the Zambezi River Valley" edited by Finn Tarp, James Juana, and Philip Ward.

P. S. Chinowsky $(\square) \cdot$ A. E. Schweikert $・$ N. L. Strzepek

Institute for Climate and Civil Systems, University of Colorado, Boulder, CO 80309-0428, USA

e-mail: paul.chinowsky@colorado.edu

K. Strzepek

Joint Program on the Science and Policy of Global Change, Massachusetts Institute of Technology,

Cambridge, MA, USA 
predicted changes, incorporate changes into mid-range and long-term development plans, and secure funding for the proposed and necessary adaptations (UNFCCC 2009, UNFCCC 2009).

Of particular concern in this area is the impact of climate change on road infrastructure. Specifically, the construction and expansion of road infrastructure is linked to economic growth, development, and social welfare (Kessides 1993). Because of their exposure to environmental conditions, transport infrastructure systems, including roads, are particularly vulnerable to climate change (Koetse and Rietveld, 2009). Therefore, the risks of climate change to roads threaten the associated economic growth, development, and social welfare benefits of infrastructure expansion.

Road investment decisions often place an emphasis on increasing the quantity and quality of infrastructure through a focus on construction and basic cost-benefit analysis approaches. Literature findings emphasize that failures in infrastructure investment in developing countries are often due to the lack of technical capacity and institutional structure in place to support successful ventures. Issues such as deficient maintenance, lack of enforcement for material and construction codes, and political interference each contribute to the lower likelihood of longterm investment success (Dabla-Norris et al. 2010).

However, a growing body of literature highlights the imperative to evaluate the impacts of climate change on infrastructure, including roads. One consistent finding in the literature is that climate change poses a threat to existing and future infrastructure, including high costs for adaptation, maintenance, and potential negative impacts on transit (Keener et al. 2013; Hambly et al. 2013; Satterthwaite 2007). The emphasis of these existing studies has primarily been awareness and the informing of public officials regarding policy implications for the infrastructure sector such as hazards that have the potential to affect the transportation infrastructure itself; its operation; and the demand for transportation (TRB 2008; Galbraith et al. 2005; AUSTROADS 2004, CCSP 2006). However, the quantification of these impacts in monetary terms or on a time-scale receives less attention (duVair, P., Wickizer et al. 2002, Oswald and McNeil 2012).

In response to this gap in the climate change literature, the authors have been actively engaged in developing specific estimates of climate change impacts on infrastructure elements. Chinowsky et al. (2011) document the potential cost impacts of climate change on road infrastructure in ten countries that are geographically and economically diverse. Additionally, other authors have extended this response methodology to determine the potential impacts from climate change on bridges (Stratus 2010) and roads in northern climates (Industrial Economics 2010). In the context of Africa, performing similar quantified studies is complicated by the lack of existing infrastructure.

In 1997, the continent of Africa (excluding South Africa) had 171,000 km of paved roads, about $18 \%$ less than Poland, a country roughly the size of Zimbabwe (IRF 2009). Despite continued investments, the stock of roads continues to lag behind the remainder of the world both in total roads and in paved roads. In 2008 only about $25 \%$ of sub-Saharan Africa's primary roads were paved, compared to a global rate of 50 and a $67 \%$ rate in North America (IRF 2009). In terms of the unpaved roads, which are the majority of the roads on the continent, more than $80 \%$ of unpaved roads are considered to be only in fair condition and $85 \%$ of rural feeder roads in poor condition and cannot be used during the wet season (Gwilliam et al. 2008; Foster and Briceño-Garmendia 2010). This disparity is especially evident in rural roads. While urbanization is an increasing trend in the developing world, in 2000 over $60 \%$ of persons in Africa still lived in rural areas; while this number is expected to decline, by 2030 approximately half of the population of Africa will still be living in rural areas (Kumar et al. 2008). This is important because poverty is often related to a lack of access to services, availability and access to healthcare, education, and markets, all of which have a 
transport component (African Union, 2005; Lombard and Coetzer, 2006; IRF 2009). As economic growth is a principal concern for most developing countries, a lack of resilient and reliable transport infrastructure, including rural roads, can reduce and hamper growth opportunities, negate benefits from investment in other sectors, and have a negative overall impact on human welfare in economic and social terms (Gachassin, et al. 2010; Lombard and Coetzer, 2006; Bryceson et al., 2006).

The current study focuses on bridging the gap between awareness and quantification by focusing on the effects of climate change on the road infrastructure of three countries in the Southern African region as part of the UNU-WIDER Development Under Climate Change (DUCC) research effort. The specific countries of interest are Malawi, Mozambique, and Zambia, all located within the Zambezi river basin. The study examines the extent to which climate change will divert resources from the further development of road infrastructure to the maintenance and adaptation of the existing infrastructure. From this perspective, the study provides an engineering-based perspective on climate change impacts. The current study advances previous work by the authors by using Hybrid Frequency Distributions as a new climate modeling input technique that provides a broader range of potential climate scenarios from which to determine possible impacts. This replace the older Koppen-Geiger mapping technique. Although the authors recognize that additional study on the compounding effects of climate change impacts and transport interruption require investigation, the study is a first step in impact determination and limits its focus to the technical impacts of climate change on road infrastructure.

\section{Study approach}

The current study incorporates two foundational components which combine to create the approach for addressing the climate change impact on road infrastructure; a policy approach and an impact methodology. The policy component focuses on whether a transportation agency desires to adopt an "adapt" or a "no adapt" policy in terms of climate change. An "adapt" strategy means that a proactive approach is taken and climate resiliency is incorporated into the design, rehabilitation, and construction of roads. This may mean a change to the design standards for a road type (for example, specifying a different binder type for asphalt) or a change in type of road constructed (for example upgrading from unpaved to gravel). Conversely, a "no adapt" strategy does not consider climate impacts during design and construction. Instead, impacts from climate change will be addressed through adjustments to ongoing maintenance, which is typically a cost from increase in maintenance frequency. In both of these strategies, the costs associated with climate impacts are based on what actions are required to maintain the original design life of that road. While it is acknowledged that hybrids of these policies will form the final decision on climate adaptation, for the purposes of this study, the dual approach provided the opportunity to analyze the potential differences in taking a reactive or proactive approach to climate change adaptation.

The second component of the study, the stressor-response methodology, forms the technical approach to adaptation and is based on the concept that exogenous factors, or stressors, have a direct effect on and subsequent response by, focal elements. In the context of climate change and infrastructure, the exogenous factors are the individual results of climate change including changes to precipitation levels, temperatures, storm frequency, and wind speeds. The focal elements are the individual infrastructure types including roads, railroads, water and power distribution, and public buildings among others. Therefore, a stressor-response value is the quantitative impact that a specific stressor has on a specific infrastructure element. 


\subsection{Hybrid frequency distributions (HFDs)}

In previous studies conducted by the authors, a set of four-to-six climate scenarios were adopted to determine a range of potential impact outcomes. In contrast, the current study employs a broader range of climate scenarios selected from a set generated by the Hybrid Frequency Distribution (HFD) approach developed by Schlosser et al. (2011). In this approach, 17 IPCC $4^{\text {th }}$ Assessment (AR4) climate models are used as a basis for generating a suite of climate scenarios (IPCC 2007). To address the uncertainty associated with climate scenario projection including downscaling, economic, and policy issues, the HFD approach incorporates a set of 400 factors from the Integrated Global Systems Model (IGSM), a multisector, multiregional model of the global economy (Sokolov et al. 2009). The economic factors of the IGSM are used to provide variance in the development and economic scenarios that may evolve throughout the timeframe of the simulations. When these scenarios are combined with the 17 climate models, a distribution of potential climate outcomes are produced at a $2^{\circ} \times 2^{\circ}$ grid throughout the globe. The result of this interaction is 6,800 discrete climate scenarios for each overall policy limit on climate change. The set of scenarios is shown by Schlosser to provide an illustration of the distribution of climate change impacts that may occur in a given global zone. These are not the probable scenarios, but the potential variance in scenarios that may occur. For the current study, an unconstrained policy is modeled to focus on the least restrictive projection of climate change scenarios. From this pool of 6,800 possible scenarios, a statistical sampling was employed to extract a set of climate scenarios that represented the breadth of the potential scenarios based on projected climate changes. The sampling resulted in a set of 425 scenarios that were used for the current study.

\subsection{Division of road inventory}

A primary analysis function of the DUCC infrastructure system is to provide cost information. Key to this analysis is data on the existing roadstock in each geographic area analysed. Where possible, existing roadstock information at a provincial level is extracted from government data. However, when only national roadstock information is available the authors use government or commercially available data for road inventory (IRF 2009). A limitation placed on the current analysis is the focus on retaining this current road inventory at its existing level throughout the lifespan of the study. Although the infrastructure analysis system is capable of incorporating static and dynamic growth models, to reduce the uncertainties in the analysis, a static inventory was adopted throughout the study. Subsequent growth models were adopted in downstream studies by additional team members that reflect issues such as development patterns and population movements. This limitation may impact the overall results in terms of maintenance and rehabilitation concerns and whether existing roads will in fact be maintained long-term.

Given the limitation on growth in the inventory, the national inventory is allocated to each province based on a geographic allocation algorithm previously developed by the authors for climate studies (Chinowsky et al. 2011). In this process, roadstock is allocated at a sub-national administrative unit based upon geographic size and characteristics, population density, and adjusted for other factors where available (including GIS information). Within each administrative unit, roadstock is allocated to grid cells of $.5^{\circ}$ latitude by $.5^{\circ}$ longitudinal (approximately $250 \mathrm{~km}$ square area). These grid cells correlate to CRU grid cells which have been the basis for previous studies by the authors (Climate Research Unit Time Series Version 2.1). For analysis purposes, it is assumed that once the roadstock is allocated to an individual grid cell, the roadstock is evenly distributed throughout the cell. Although this may ignore specific instances 
of rivers, inclines, or other natural occurrences that impact road placement, this is an equivalent level of detail to the climate data and thus is appropriate for the overall analysis being conducted in the study.

To ensure that the allocation of road inventory to administrative levels correctly correlates to the HFD data provided, the $2^{\circ}$ latitude by $2^{\circ}$ longitudinal HFD climate data and the provincial mapping of the countries are translated to the .5 by $.5^{\circ} \mathrm{CRU}$ grids based on latitude and longitude. This allows the analysis of climate impact on the roadstock as previously mapped by the authors.

\subsection{Impact functions}

Given the climate models and the road inventory, the study approach utilizes a stressorresponse methodology based on the concept that specific road materials and components will have specific responses to external stressors such as precipitation, flooding, and temperature. The methodology is not intended to be all-inclusive in terms of the broad set of factors that may impact road degradation such as land use, population movements, alterations in freight movement and localized geography. Rather, the functions provide a high-level indicator of the isolated effects that may occur given changes in factors such as precipitation and temperature. As such, the stressor-response factors introduced below have been developed based on the engineering and materials response affects that individual material and elements have based on the specific stressors. These effects are then applied to specific circumstances such as pavement or gravel where the stressors are applied based on the climate context. The development of these factors is based on multiple inputs. A combination of material science reports, usage studies, case studies, and historic data were used to develop response functions for the infrastructure categories. Where possible, data from material manufacturers was combined with historical data to obtain an objective response function. However, when these data were not available, response functions were extrapolated based on performance data and case studies from sources such as Departments of Transportation or government Ministries. A complete discussion of the impact functions is provided in Chinowsky and Arndt (2012) including both impact functions for new construction and for maintenance improvement.

The stressor-response factors are divided into two general categories: impacts on new construction costs and impacts on maintenance costs. New construction cost factors focus on the additional cost required to adapt the design and construction when rehabilitating an asset to changes in climate expected to occur over the asset's lifespan. Maintenance cost effects are those maintenance costs, either increases or decreases, which are anticipated to be incurred due to climate change to achieve the design lifespan if construction standards have not been adjusted. In each of these categories, the underlying concept is to retain the design life span for the structure.

\subsubsection{Stressor-response values for new construction costs}

The derivation of the stressor-response values for new construction costs encompasses two general approaches. Each approach retains the focus of building a new infrastructure component to a standard that enables it to withstand projected climate changes over its design lifespan. The first approach estimates stressor-response values based on the cost associated with the change in material requirements, while the second emphasizes adaptation to an alternate infrastructure type. The materials approach is used to generate stressor-response values for paved roads and gravel roads. 
The materials methodology is based on the premise that roads should be constructed to a level that anticipates the future changes in climate conditions and the accompanying changes in material requirements. Following this concept, this methodology determines if new structures such as paved roads will be subject to material changes if it is anticipated that a significant climate change stressor will occur during their projected lifespan. Similarly, the second option for adaptation for new construction is to alter the type of infrastructure being constructed to one that has the capacity to handle the anticipated climate change. For example, where climate change is anticipated, then a consideration has to be made for dirt roads by either increasing maintenance costs as described below or altering these roads to be gravel roads. For gravel roads, the cost of adaptation is based on the need to strengthen the road with a crushed gravel mix. The benefit with this approach is that basic maintenance and climate induced maintenance is eliminated during the roads lifespan.

\subsubsection{Stressor-response values for maintenance costs}

The cost estimates for maintenance differs between paved, gravel, and unpaved roads. For paved roads, an approach is adopted that bases the cost of maintenance on the cost of preventing a reduction in lifespan. The implementation of this approach involves two basic steps: (1) estimating the lifespan decrement that would result from a unit change in climate stress and (2) estimating the costs of avoiding this reduction in lifespan. To estimate the reduction in lifespan that could result from an incremental change in climate stress, it is assumed that such a reduction is equal to the percent change in climate stress, scaled for the stressor's effect on maintenance costs.

For gravel and dirt roads, maintenance impacts are induced by changes in maximum monthly precipitation rates. The result of increased precipitation is increased erosion, creating a need to increase maintenance to retain the original design life. To estimate the changes in road maintenance costs, the amount of erosion is used as a basis for determining the percentage of maintenance increase required. The calculation of the erosion rates for dirt and gravel roads is based on three factors: precipitation amount, traffic levels, and slope of the road. In terms of precipitation, studies indicate that a $1 \%$ increase results in an approximate $1 \%$ impact on the design life in a minimal slope condition with low traffic levels (Dubé et al. 2004). This is used as the base condition for maintenance calculations. However, this base case is augmented as traffic rates and slope percentages increase, resulting in significantly greater erosion rates.

\subsection{Flooding}

Similar to precipitation and temperature, flooding damage is calculated through a set of stressor-response functions. However, due to the unique attributes of flooding, the damage functions have characteristics that are unique from the precipitation and temperature functions. Specifically, road losses are calculated based on monthly runoff estimates and a custom damage function that generates loss estimates based on the return period of the precipitation intensities (Chinowsky and Arndt 2012). The damage function is derived by assuming damage begins at the 2 year frequency and grows linearly to $100 \%$ damage at the 100 year event. While this is valid for road culvert damage, it does not consider other damages that may be incurred beyond culvert washout. These other damages include damages in riverside floodplains, other washouts, etc. These damages typically occur as a result of infrequent events. Therefore, this basis is used for events with recurrence intervals 20 years or less. For events greater than 20 years, and less than or equal to 50 years, it is assumed that an increase in the fraction of roadway damages would occur. 
Translating the runoff and damage curve estimates into damage costs requires two steps: determining the amount of road kilometers damaged and the specific costs implied by these damages. The first of these steps requires translating information on floods into actual kilometers of road that will be damaged. This determination is dependent on two factors; the intensity of the flood and how many roads have had climate-resilient adaptations applied to them. For paved roads, the accomplishment of this task is based on the type of roads that are being damaged and the standard maintenance costs these roads incur. For example, annual maintenance costs for primary roads are estimated at $15 \%$ of construction cost, while 29 and $35 \%$ are used for secondary and tertiary roads respectively. The primary roads number is lower due to the roads being built to a higher standard at original construction (COWI 2009).

\section{Study results}

Utilizing the data compiled for the current study together with the described approach, the three southern African countries examined in this paper are facing a potential \$596 million price tag based on median climate scenarios to maintain and repair roads as a result of damages directly related to temperature and precipitation changes from potential climate change through $2050 .^{1}$ This cost is strictly to retain the current road inventory. This cost does not include any costs associated with impacts to roads added above the current inventory or to rehabilitate roads that may exist below design standard currently. As detailed in Table 1, if these African countries focus on a reactive response to climate change, where the repair of additional climate change damage is completed on an annual basis with no adaptive changes to infrastructure elements the total cost projections through 2050 could increase to $\$ 772$ million at the $75^{\text {th }}$ percentile level.

These same numbers can be put in the perspective of Opportunity Cost to determine the relative effect of climate change on the continent based on the kilometres of paved roads that cannot be built, or the kilometres of unpaved roads that cannot be upgraded, due to reallocation of funds to react to climate change damage. It is assumed in this metric for illustrative purposes that the funds are being allocated from in-country funds rather than external investments. Therefore, limited funds are available for addressing climate impacts. Utilizing this measure, Malawi, Mozambique, and Zambia are facing a potential opportunity cost of 13, 15, and $11 \%$ respectively if no pre-emptive action is taken based on the median climate scenarios. This opportunity cost translates into a lost potential of expanding the existing paved road network in the countries either with new roads or with upgrades to existing unpaved roads by 3,530 , 3,213 , and $8,760 \mathrm{~km}$ of paved road respectively.

These results are modified if a proactive adaptation response is implemented. As described previously, if adaptation options are implemented such as changing dirt roads to gravel surfaces, or increasing the base depth of gravel roads, the impact of climate change can be reduced. When these adaptations are put in place in scenarios where climate impacts are anticipated, the total impact costs are changed (Table 1). As illustrated, the total costs for the three countries under the median and $75^{\text {th }}$ percentile scenarios are changed to $\$ 1.09$ billion and $\$ 1.17$ billion respectively. Although as a group this represents an increase in total costs, the benefits vary between countries. Malawi sees a distinct benefit from adaptation while Mozambique and Zambia incur a net increase in cost from adaptation.

The reason for a net increase resulting from adaptation resides in a combination of using foresight to determine adaptation and the length of life of roads. If perfect foresight anticipates that at some point in the future life of the road that climate change may impact the road, then

\footnotetext{
${ }^{1}$ All costs are provided in US Dollars using a $5 \%$ discount rate to 2010 dollars.
} 


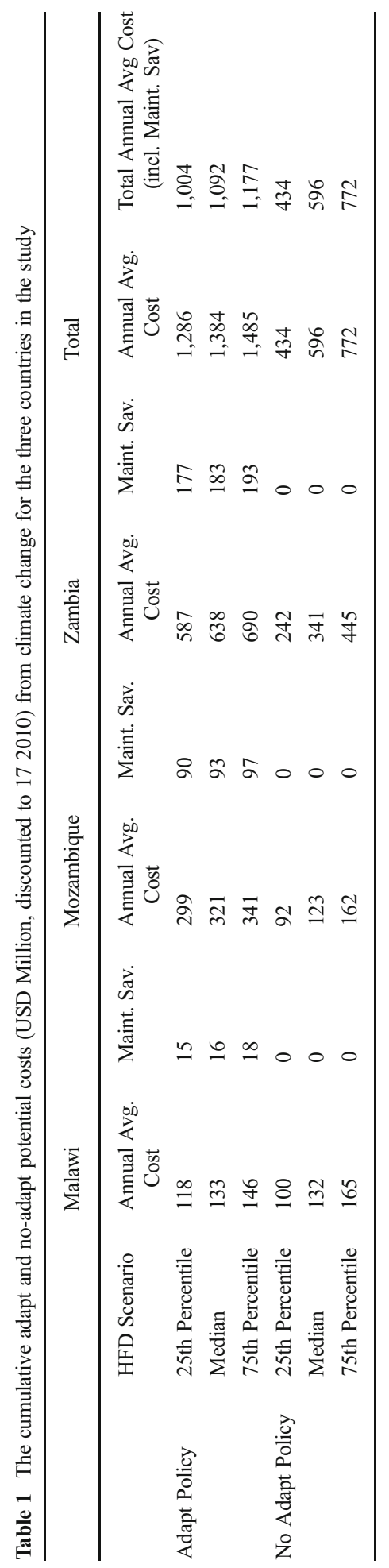


the adaptation policy requires the road to be adapted through an appropriate upgrade at the time of construction or rehabilitation. Given that the impact may not occur for 15 years after the adaptation is put in place, discounting will minimize the long-term benefit versus the shortterm cost increase.

In addition to this variance that occurs with the implementation of an adaptation policy, variance must be examined in terms of the distribution of the potential impacts based on the climate scenarios. In the current study incorporating the 425 HFD climate scenarios, the three countries have distinct distributions of potential impacts for the "No Adapt" Policy scenario (Fig. 1). For the "Adapt" Policy scenario (not shown), between 70 and $90 \%$ of the HFD climate scenarios project results in the lowest bin of results. This shows that while the Median and $75^{\text {th }}$ percentile "Adapt" costs are higher than the "No Adapt" cost for Mozambique and Zambia, the majority of climate projections are on the very low end of weighted distribution in terms of total cumulative cost. This variance is a critical question in determining appropriate adaptation policies. Specifically, the uncertainty associated with climate modeling makes each of the scenarios equally likely to occur. Therefore, results such as the median and maximum should not be confused with likelihood, but rather, must be read as the number of models predicting such an outcome.

Maintenance savings are included in the current study in terms of adapting unpaved roads. Since unpaved roads are susceptible to increases in precipitation as well as traffic increases, when precipitation increases are anticipated that exceed the maximum monthly threshold, unpaved roads are altered to be gravel surfaces. This adaptation is a front-end expense, however it concurrently provides longer life for the road and eliminates $90 \%$ of the annual maintenance associated with the road since gravel surfaces require significantly less maintenance than dirt surfaces. This savings is reflected in the Maintenance Savings entry in Table 1. Zambia sees the greatest savings at just under \$200 million average annual savings.

\subsection{Malawi}

At a country level, Malawi lies in the middle of the three countries in terms of national impact under the no adaptation policy with a total annual average cost of \$165 million USD. As illustrated in Tables 1 and 2, Malawi is the only country that sees an economic benefit from adaptation prior to any other considerations being put in place. This savings is increased when maintenance savings is incorporated into the analysis.

When viewed on a decade basis, the first decade between 2011 and 2020 reveals the front-end cost associated with adapting roads through the adaptation policy. However, as the decades progress, the long-term savings is reflected in the adaptation costs becoming increasingly lower than the no adaptation policy. As seen in Table 2, as the roadstock is adapted to mitigate future climate impacts, the number of kilometres that have not been adapted and are thus potentially susceptible to impact by climate change is reduced. In contrast, the no adaptation policy does not reflect this reduction and shows a constant financial impact from the climate change scenarios.

The overall totals when divided between the decades reflect the narrow distribution of the climate scenarios. The difference between the 25th and 75th adapt scenarios is consistent between the first and fourth decades with a maximum of a $34 \%$ increase from the 25 th to the 75 th percentile impact values. Once again, this distribution is skewed towards the lower half of the distribution groupings.

\subsection{Mozambique}

Mozambique consistently incurs a higher economic cost through the adaptation policy when compared to a no adaptation policy (Table 2). However, Mozambique obtains a 


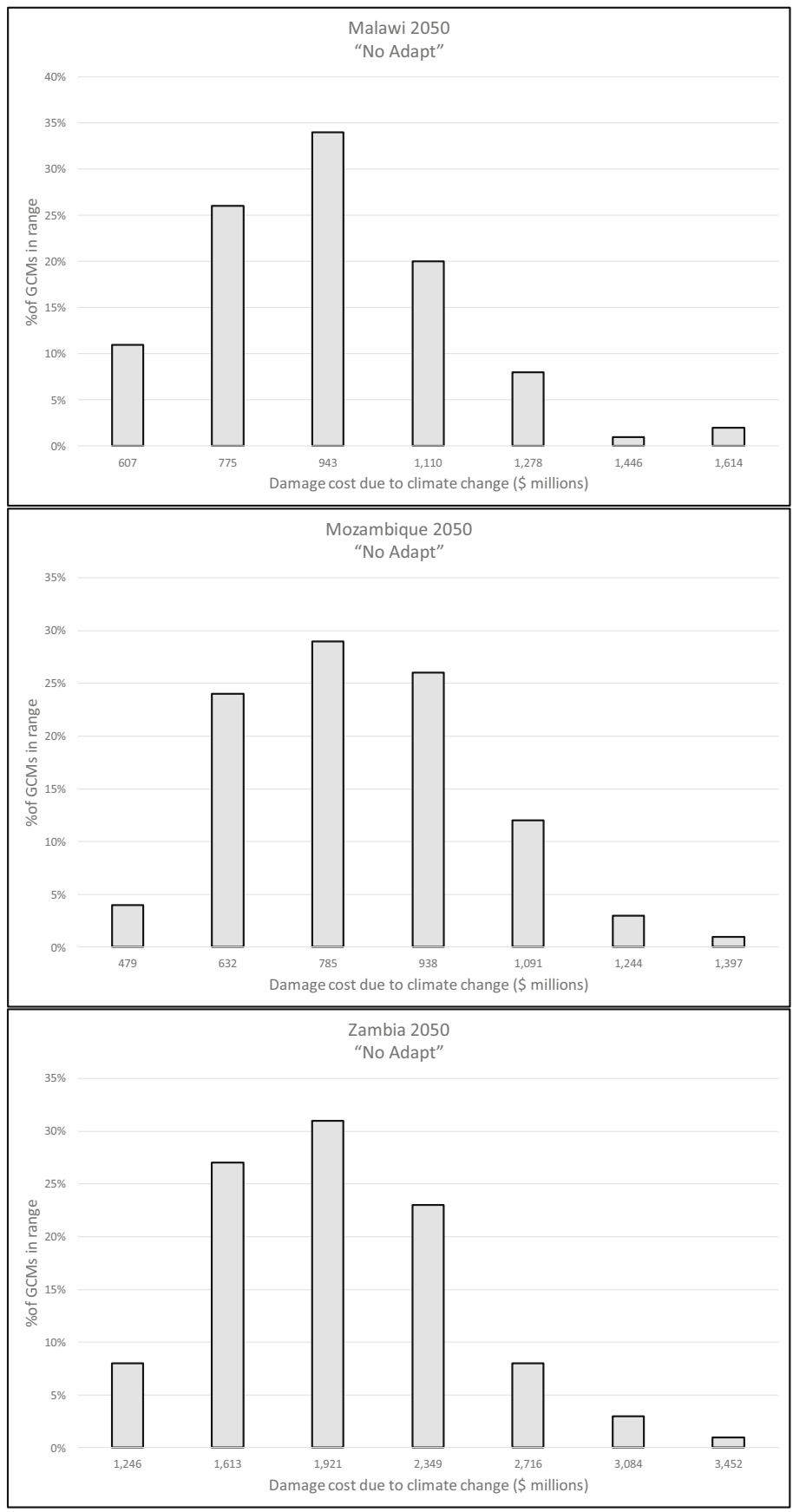

Fig. 1 No adapt histogram for Malawi, Mozambique, Zambia

savings of $29 \%$ in the median scenario to only $13 \%$ for Malawi. This savings is a direct result of the larger percentage of unpaved roads that exist in Mozambique. The 
Table 2 The median level decadal impacts for the adapt and no-adapt scenarios (\$USD 21 Million, discounted to 2010)

\begin{tabular}{|c|c|c|c|c|c|c|c|}
\hline \multirow{3}{*}{$\begin{array}{l}\text { Decade } \\
2020\end{array}$} & \multirow{3}{*}{$\begin{array}{l}\text { Policy } \\
\text { Adapt }\end{array}$} & \multicolumn{2}{|l|}{ Malawi } & \multicolumn{2}{|c|}{ Mozambique } & \multicolumn{2}{|l|}{ Zambia } \\
\hline & & Total cost & Opp. cost & Total cost & Opp. cost & Total cost & Opp. cost \\
\hline & & 68 & $7 \%$ & 192 & $23 \%$ & 383 & $13 \%$ \\
\hline & No adapt & 33 & $3 \%$ & 33 & $4 \%$ & 90 & $3 \%$ \\
\hline \multirow[t]{2}{*}{2030} & Adapt & 38 & $4 \%$ & 77 & $9 \%$ & 139 & $5 \%$ \\
\hline & No adapt & 29 & $3 \%$ & 30 & $4 \%$ & 80 & $3 \%$ \\
\hline \multirow[t]{2}{*}{2040} & Adapt & 16 & $2 \%$ & 35 & $4 \%$ & 72 & $2 \%$ \\
\hline & No adapt & 38 & $4 \%$ & 33 & $4 \%$ & 88 & $3 \%$ \\
\hline \multirow[t]{2}{*}{2050} & Adapt & 10 & $1 \%$ & 17 & $2 \%$ & 41 & $1 \%$ \\
\hline & No adapt & 34 & $3 \%$ & 30 & $4 \%$ & 80 & $3 \%$ \\
\hline \multirow[t]{2}{*}{ Total } & Adapt & 132 & $13 \%$ & 321 & $38 \%$ & 635 & $21 \%$ \\
\hline & No adapt & 134 & $13 \%$ & 126 & $15 \%$ & 338 & $11 \%$ \\
\hline
\end{tabular}

combination of the projected increase in precipitation with the large percentage of unpaved roads results in the greater percentage basis of maintenance savings - \$90-97 million annually (Table 1).

As illustrated in Tables 1 and 2, the adaptation scenario sees a continuing reduction in costs while the no adaptation scenario sees a consistent impact across the time series. The distribution of the decadal results illustrates a small variance between the potential scenarios. The maximum variance between the 25 th and 75 th adapt scenarios is only $18 \%$ and occurs in the first decade. This variance reflects the even distribution of the scenario results in a pattern that is close to a normal distribution.

\subsection{Zambia}

At a country level, Zambia incurs more than double the potential economic impacts from climate change than either Malawi or Mozambique. This economic figure is a result of Zambia having over $20,000 \mathrm{~km}$ of roads which is three times the amount of either of the other two countries. However, the large number of roads translates to maintenance savings as Zambia contains a significant percentage of unpaved roads that are susceptible to climate change impacts. This causes an adaptation policy to have an average annual maintenance savings of \$177-193 million.

The decadal analysis illustrates how the relative costs from the adaptation policy decrease as more roads are adapted over time (Table 2). The savings are particularly apparent in the last decade as changes in climate increasingly cause damage to roads under the no adaptation policy. However, as the roadstock inventory is adapted to future impacts under the adaptation policy, the level of maintenance required to mitigate the damage is consistently reduced.

In terms of variance in the scenarios, the distribution pattern is clustered around the 2 nd and 3rd groups in the overall distribution pattern resulting in a similar variance to Malawi between the 25th and 75th percentile impact numbers. The greatest variance for Zambia is in the first decade where the variance between the 25 th and 75 th percentile figures raises to $20 \%$. However, this variance reduces as the discounting impacts the results and the decades progress to a variance of only $10 \%$ in the final decade. 


\section{Limitations}

The current study is based on several key components which introduce uncertainty into the quantitative analysis within the study. The climate data presented here is based on input from a single source, using an innovative new approach in Hybrid Frequency Distributions. Additionally, the study relies on existing material studies to derive the impact stressors. Although the study bases its findings on recognized authorities and studies, the quantitative cost estimates are dependent on the findings from these and similar studies. Issues such as specific pavement types, local conditions, construction and maintenance techniques can all combine to impact specific cost impacts. Additionally, impacts do not occur in a linear fashion. Compounding effects exist between factors and extreme events have disproportionate effects that cannot be captured in the general models presented here. Therefore, the quantitative cost results may differ based on alternative studies.

These limitations should be considered when analyzing the quantitative results of this study. However, the qualitative relationships presented here will remain consistent even if the referenced studies are altered. Specifically, the relative impact on the countries in the study will remain consistent and the overall findings remain as stated.

\section{Discussion and conclusion}

The importance of roads to development and long-term growth in the Southern Africa region requires public officials to balance short-term needs versus long-term planning. The addition of potential climate change effects increases the requirement for balance as the potential benefit from a decision may not appear for several decades. The developed stressor-response functions illustrate the potential to integrate the predicted temperature, flooding, and precipitation changes resulting from climate change with traditional costing methods to anticipate cost impacts in specific locations.

Although the gross dollar impact varies between countries due to individual road inventories and climate impacts, the impacts will force every country to transfer a proportion of annual expenditures to offset the effects of climate change on road infrastructure. On a country level, potential cumulative costs for the countries in the study may exceed $\$ 923$ million with a reactive approach to climate change. However, total costs do not reflect the complete impact. Rather, it is the opportunity cost associated with these total costs that create the potential hardship for each country. As indicated in the study, individual countries face the prospect of losing the opportunity to expand current paved networks by $23,000 \mathrm{~km}$ if a reactive approach is adopted and $20,500 \mathrm{~km}$ if a proactive approach is adopted.

In conclusion, the results from the current study are intended to provide an initial, highlevel overview of the potential impacts that climate change may have on individual road inventories. The resulting challenge to governments from the final results of this analysis will be how to incorporate a multitude of conflicting requirements into a cohesive policy that achieves balance between short-term needs and the potential long-term effects of climate change on infrastructure.

\section{References}

Africa Union, UN Economic Commission for Africa. "Transport and the millennium development goals in Africa". February 2005 
AUSTROADS (2004) Impact of climate change on road infrastructure. Austroads Publication No. AP-R243/04, Sydney, Australia

Bryceson, D., et al. (2006) "Roads to Poverty Reduction? Dissecting rural roads" impact on mobility in Africa and Asia." Reducing Poverty and Inequality: How can Africa be included

CCSP (2006) Effects of climate change on energy production and use in the United States. U.S. Climate change science program, department of energy, Washington DC

Chinowsky P, Arndt C (2012) Climate change and roads: a dynamic stressor-response model. Rev Dev Econ 16(3):448-462

Chinowsky PS, Hayles C, Schweikert A, Strzepek N (2011) Climate change as organizational challenge: comparative impact on developing and developed countries. Eng Proj Org J 1(1):67-80

COWI (2009) Making transport climate resilient. Report to the World Bank, Document P-70922A_02, Washington DC

Dabla-Norris, Era, Brumby, Jim, Kyobe, Annette, Mills, Zac and Papageorgiou, Chris (2010) "Investing in public investment: an index of public investment efficiency," IMF working paper 11/37, international monetary fund

Dubé K, Megahan W, McCalmon M (2004) Washington road surface erosion model. Prepared for State of Washington Department of Natural Resources. February 20, 2004

duVair, P., Wickizer, D. Bruer, M.J. (2002) "Climate change and potential implications for California's transportation system. In the potential impacts of climate change in transportation: workshop summary and proceedings. U.S. Department of Transportation, Center for Climate Change and Environmental Forecasting, Washington D.C

Industrial Economics (2010) Costing climate impacts and adaptation: a Canadian study on public infrastructure. Report to the national round table on the environment and the economy, Canada

Foster V, Briceño-Garmendia C (2010) Africa's infrastructure: a time for transformation. Africa development forum, World Bank, Washington DC

Gachassin, Marie, Boris Najman, and Gaël Raballand (2010) Roads impact on poverty reduction-a cameroon case study. World Bank Policy Research Working Paper 5209

Galbraith RM, Price DJ, Shackman, L (2005) Scottish road network climate change study. Scottish executive

Gwilliam K, Foster V, Archondo-Callao R, Briceño-Garmendia C, Nogales A, Kavita S (2008) Africa infrastructure country ciagnostic: roads in Sub-Saharan Africa, summary of background paper 14. World Bank, Washington DC

Hambly D, Andrey J, Mills B, Fletcher C (2013) Projected implications of climate change for road safety in greater Vancouver, Canada. Climate Change 116(3-4):613-629

IPCC (2007) Climate change 2007: synthesis report. In: Pachauri RK, Reisinger A (eds) Contribution of working groups I, II and III to the fourth assessment report of the intergovernmental panel on climate change. IPCC, Geneva

IRF (2009) World road statistics 2009. International Road Federation, Geneva

Kaberuka D (2009) Kaberuka: Africa needs usd 40 billion/year in climate aid. Afr Dev Bank Group 12(02):2009

Keener, V.W., Marra, J.J., Finucane, M.L., Spooner, D., and Smith, M.H (2013) Climate change and pacific islands: indicators and impacts: report for the 2012 pacific islands regional climate assessment. Island press

Kessides, C (1993) The contributions of infrastructure to economic development a review of experience and policy implications, The World Bank, Washington, D.C

Koetse, M. and P. Rietveld (2009) The impact of climate change and weather on transport: an overview of empirical findings. Transportation Research Part D, 205-221

Kumar, Ajay \& Barrett, Fanny (2008) Stuck in traffic: urban transport in Africa. Africa infrastructure country diagnostic. The World Bank Group. January 2008

Lombard, P., and L. Coetzer (2006) The estimation of the impact of rural road investments on socio-economic development

Oswald MR, McNeil S (2012) Climate change adaptation tool for transportation: Mid-Atlantic region case study. J Transp Eng 139(4):407-415

Satterthwaite, D (2007) Adaptation options for infrastructure in developing countries, A Report to the UNFCCC financial and technical support division, UNFCCC, Bonn, Germany

Schlosser, A., Gao, X., Strzepek, K., Sokolov, A., Forest, C., Awadalla, S., and Farmer, W. (2011) Quantifying the likelihood of regional climate change: a hybridized approach, Report 205, MIT joint program on the science and policy of global change, October 2011

Sokolov, A. P., Stone, P. H., Forest, C. E., Prinn, R., Sarofim, M. C., Webster, M., \& Jacoby, H. D (2009) Probabilistic forecast for twenty-first-century climate based on uncertainties in emissions (without policy) and climate parameters. Journal of Climate, 22(19) 
Stratus Consulting (2010) "Climate Change Impacts on Transportation Infrastructure." Report Prepared for U.S. Environmental Protection Agency, Stratus Consulting, Boulder, CO

TRB (2008) Potential impacts of climate change on U.S. Transportation, TRB special report 290. Transportation research board, Washington, DC

UNFCCC (2009) Support needed to fully implement national adaptation programmes of action (NAPA's), least developed countries. LDC Expert Group 2009. UNFCCC 